\title{
General analysis of factors influencing cataract surgery practice in Shanghai residents
}

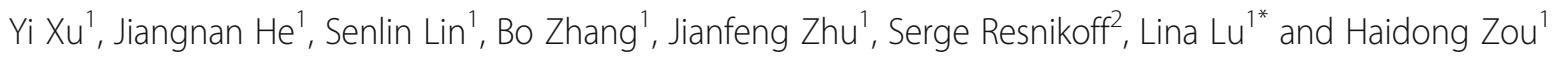

\begin{abstract}
Background: It was reported that lack of knowledge, less confidence of medical services, commute difficulties, and poor economic conditions would be the main barriers for cataract surgery practice. The influencing factors could have changed in cities with high developing speed. Shanghai is one of the biggest cities in China and the world. The purpose of the study was to explore the factors influencing cataract surgery practice in Shanghai.

Methods: This was a population-based, cross-sectional study. A total of 2342 cataract patients older than 50 years old with cataract-induced visual impairment or who had undergone cataract surgery were recruited from rural and urban areas of Shanghai. Participants accepted a face-to-face structured questionnaire. Data were collected on patient demographics, education, work, income, health insurance, awareness about cataracts disease, treatment and related medical resources and deration policy, transportation and degree of satisfaction with hospitals.

Results: There were 417 patients who had received cataract surgery, 404 of them supplied complete information in the questionnaire. More female subjects (64.6\%) than male subjects (35.4\%) accepted cataract surgery among the 404 patients. Of the patients with cataract history, $36.4 \%$ of surgery patients were equal or older than 80 . More people with urban medical insurance received surgery $(p=0.036)$. Patients who received surgery were more satisfied with local medical service ( $p=0.032$ ). In urban area, Lower income and difficulties with commutes were related to a higher rate of surgery.

Conclusions: Cataract patients with the following features were more inclined to receive surgery: female, old age, better awareness. In urban areas low income and difficult commutes did not represent barriers for cataract surgery, probably because of appropriate cataract surgery promotion policies recent years in Shanghai. In rural areas, better healthcare reimbursement policies would likely lead to a higher uptake of cataract surgery. Further cohort studies with more controls could supply stronger evidence for our viewpoint.
\end{abstract}

Keywords: Cataract surgery, Influencing factor, Economy, Policy, Questionnaire

\section{Background}

According to the World Health Organization (WHO) report, cataracts were responsible for blindness in 10.8 million people around the world, or $33.4 \%$ of all blindness [1]. As such, it is a leading cause of avoidable blindness [2-4]. By 2020, the estimated cost required to treat the burden of avoidable blindness and visual impairment

\footnotetext{
*Correspondence: linaluoph@163.com

'Shanghai Eye Disease Prevention \& Treatment Center / Shanghai Eye Hospital; Shanghai Key Laboratory of Ocular Fundus Diseases; Shanghai General Hospital; Shanghai Engineering Center for Visual Science and Photomedicine, 380 Kangding Road, Shanghai 200040, China Full list of author information is available at the end of the article
}

over 10 years will be US\$23.1 billion [5]. In China, agerelated cataracts are still the leading cause of treatable blindness $[6,7]$. However, China has one of the lowest cataract surgery rates (CSR) in Asia [8-10], with clear disparities across different areas [11]. In 2014, the CSR was 1125 per 1,000,000 per year [12]. China's CSR was much lower than that of developed countries and some developing areas such as Latin America [13]. In areas with low CSR, cataract surgeries are often postponed until the disease progresses to a worse condition, by which time there are more surgery risks and complications [14]. There is no standardized medical referral

(C) The Author(s). 2018 Open Access This article is distributed under the terms of the Creative Commons Attribution 4.0 International License (http://creativecommons.org/licenses/by/4.0/), which permits unrestricted use, distribution, and 
system in China; nearly all of the hospitals are walk-in, and a severe imbalance exists in the distribution of ophthalmologic medical resources. Cataract patients who want to receive surgery have to travel a long way if there are no cataract hospitals near their home. It was reported that [15] the following four problems could be primary barriers to basic cataract surgery: lack of knowledge about cataracts, low confidence in the quality of local medical services, transportation difficulties, and poor economic conditions. However, the major factors influencing cataract surgery may differ across various areas [16].

In recent years, rapid development has occurred in many areas of China, and an imbalance exists across various geographical districts and people with regard to medical resources, infrastructure, financial conditions, education level, health awareness status, and so on [17, 18]. Shanghai, which is undergoing dramatic urbanization, has one of the most rapid rates of development in China and in the world. The availability and affordability of medical services in Shanghai is relatively optimal compared to most developing districts of China $[19,20]$. Over the past 15 years, the Shanghai government has been putting policies into practice to promote cataract surgeries. Shanghai's cataract surgery rate has been rapidly increasing during the last 10 years. However, the administration of cataract surgery practice is still met with big problems in some populations. To analyse the major factors influencing cataract surgery, we enrolled 2342 Shanghai residents who had undergone cataract surgery or with cataract-induced visual impairment whose presenting visual acuity (PVA) was less than $20 / 40$, and collected various information on population features, social economics, medical resources and patients' health awareness status. The aim was to investigate the possible reasons for unoperated cataracts, which cause vision impairment, in a population-based study.

\section{Methods}

\section{Study setting and population}

This study was approved by the Ethics Committee of the Shanghai Eye Disease Prevention \& Treatment Center. It was carried out in accordance with the Declaration of Helsinki. It was executed from June to November 2014 [21]. The Baoshan and Xuhui districts were randomly selected as representative rural and urban areas in the present study, respectively. Cluster sampling was used based on community unit, the sample of individuals were randomly selected. The study sampling frame for each community was constructed using geographically defined clusters based on register census data. Each cluster contained a population of approximately 1000 individuals (all ages). Basing on the percentage of population of older than 50 years old, we randomly selected 24 and
19 clusters (with equal probability) from the sampling frame of Baoshan and Xuhui districts. Finally, 11,644 residents $\geq 50$ years old were enrolled [21, 22]. Ophthalmologic examinations were performed on each subject. Those patients who had undergone cataract surgery or who presented with cataracts and presented visual acuity (PVA) in the better eye worse than 20/40 (mild visual impairment) were chosen for the questionnaire survey. The diagnostic criteria for cataract was that patients' lens opacity was commensurate with visual impairment and no other abnormality could account for the decrease in visual acuity. The definition of cataract-induced visual impairment was: Besides cataract, there were no other abnormality could account for the decrease in visual acuity, and PVA in the better eye worse than 20/40 [22]. Participation in the study was encouraged by the mayors of the communities. A total of 2542 patients were eligible for the study, and 2342 patients accepted the questionnaire survey, 2234 of them supplied complete information required by the questionnaire. The response rate was $92 \%$.

\section{District information}

The Baoshan district is in the northern part of Shanghai, and the Xuhui district is located in the southwest. The land areas of Baoshan and Xuhui cover $270.99 \mathrm{~km}^{2}$ and $54.76 \mathrm{~km}^{2}$, respectively. According to the report from the "Shanghai Statistical Yearbook 2015", the year-end populations in 2014 were 2.024 million (Baoshan) and 1. 110 million (Xuhui). According to the 2014 report from the Shanghai eye diseases prevention and treatment information management system, the district CSRs were 2951 (Baoshan) and 4548 (Xuhui), and the CSR for the entire city was 3807 . The details are shown in Table 1.

\section{Medical resources}

There are 5 hospitals in Baoshan district in which 16 cataract surgeons perform surgery regularly. Compared to Baoshan district, Xuhui district has many more hospitals and cataract doctors (8 hospitals and 120 cataract surgeons) (Table 1).

\section{Patients}

Door-to-door recruitment was conducted and written informed consent was acquired from each participant. Ophthalmic examination and questionnaire surveys were conducted at local community healthcare centers. All of the participants were 50 years old or older. Patients underwent ophthalmic examinations performed by professional optometrists and an ophthalmologist, including distance-presenting visual acuity (PVA) tested by a retro illuminated tumbling E LogMAR chart; intraocular pressure (IOP); fundus photography; and slit-lamp examination of eyelid, ocular globe, pupillary reflex, lens grade 
Table 1 District information and cataract medical resources in Baoshan \& Xuhui districts

\begin{tabular}{llllll}
\hline & Land area $\left(\mathrm{km}^{2}\right)$ & Population (million) & CSR in 2014 & $\begin{array}{c}\text { Number of hospitals } \\
\text { for cataract treatment }\end{array}$ & $\begin{array}{l}\text { Number of doctors } \\
\text { being able to do } \\
\text { cataract surgery }\end{array}$ \\
\hline Baoshan & 270.99 & 2.024 & 2951 & 5 & 16 \\
Xuhui & 54.76 & 1.110 & 4548 & 8 & 120 \\
Total & 325.75 & 3.134 & 3750 & 13 & 136 \\
\hline
\end{tabular}

and fundus. Cataract was assigned when lens opacity was observed, if a previous cataract surgery was reported, or if signs of cataract or previous cataract surgery were observed in slit-lamp examination. For patients who had received cataract surgery, we recorded the surgery type, IOL (intraocular lens) position, posterior capsule status and other complications. A total of 2542 cataract patients (1312 rural, 1230 urban) with PVA in the better eye worse than $20 / 40$ were selected for the following questionnaire survey.

\section{Questionnaires}

There were 2342 cataract patients who accepted the interview. Face-to-face visits were conducted by four primary healthcare professionals. The four professionals were well-trained before they conducted the work, and consistency checks were performed. The following information was collected during the survey:

1. Basic information: age, gender, education, work, medical insurance, family disposable income per month.

2. Patients' awareness: awareness about cataracts (4 questions); awareness about cataract surgery, including treatment and proper surgery access, long-term complications from untreated cataracts, whether it is painful and how long it takes to recover after the surgery (7 questions); awareness about cataract medical resources and deration policy, including whether they know which hospitals in the district perform cataract surgery, knowledge about cataract surgery cost and the reimbursement policy (6 questions). Each question in this part was scored "1", "2", "3" or "4" when the answer was "nothing", "a little knowledge", "basic knowledge" or "good knowledge", respectively. Scores from 17 questions about awareness were summed for each patient.

3. Transportation: How long does it take to travel from your home to the nearest cataract surgery hospital? How many transfer times of the transportation would you need? The reason that we identified transfer times as a potential risk factor is that most older people in China do not know how to drive or do not drive; instead, they usually take public transportation. Transfer times could therefore limit accessibility to cataract hospitals.

4. Satisfaction with local hospitals: Are you satisfied with the facilities and medical service of the hospitals nearby?

The study abided by the tenets of the Declaration of Helsinki. It was approved by the Shanghai Eye Disease Preventive \& Treatment Center Committee of Ethics.

\section{Statistical analyses}

All statistical analyses were performed using STATISTICAL ANALYSIS SYSTEM (SAS 9.2, SAS Institute, Inc., Cary, NC. USA). Statistical significance was determined at $p<0.05$. Absolute frequency (n) and relative frequency (\%) were calculated, and Pearson chi-square $\left(X^{2}\right)$ tests were used for the qualitative variables. Means and SDs (mean \pm SD) were calculated, and logistic analysis and univariate ANOVA were applied to the quantitative variables. Multivariate logistic regression models were constructed to assess the association with surgery status, including gender, age, income, education, social insurance, hospital accessibility, satisfaction about hospital facilities, satisfaction about medical service, awareness score and district as the independent variables. The subgroup analysis within rural area or urban area about the association with surgery status were also shown. Odds ratios (ORs), 95\% confidence intervals (CIs), and $p$ value are also presented in Table 4.

\section{Results}

Clinical information derived from questionnaire interview All of the selected patients underwent ophthalmologic examination. PVA, IOP and lens status are shown in Table 2. Most of the patients in rural and urban areas had PVA between $20 / 63$ to $<20 / 40$. Of patients in rural and urban areas, $13.2 \%$ and $15.4 \%$, respectively, had PVA worse than 20/400. The average IOPs were $16.9 \pm 3$. $9 \mathrm{mmHg}$ in rural patients and $15.8 \pm 4.0 \mathrm{mmHg}$ in urban patients $(p=0.12)$. Among the 2342 interviewees, there were 417 patients who had received cataract surgery and 1925 patients had not. 
Table 2 Ophthalmologic examination of subjects accepted questionnaire interview in rural and urban

\begin{tabular}{llll}
\hline & $\begin{array}{l}\text { Rural } \\
n=1312\end{array}$ & $\begin{array}{l}\text { Urban } \\
n=1230\end{array}$ & $P$ value \\
\hline PVA & & & 0.16 \\
$<20 / 40-20 / 63$ & $803(61.2 \%)$ & $758(61.5 \%)$ & \\
$20 / 63-20 / 200$ & $312(23.8 \%)$ & $259(21.1 \%)$ & \\
$20 / 200-20 / 400$ & $24(1.8 \%)$ & $24(2.0 \%)$ & \\
$<20 / 400$ & $173(13.2 \%)$ & $189(15.4 \%)$ & \\
IOP (mmHg) & $16.9 \pm 3.9$ & $15.8 \pm 4.0$ & 0.12 \\
Lens status & & & 0.004 \\
cataract & $1084(82.6 \%)$ & $937(83.6 \%)$ & \\
IOL & $129(10.5 \%)$ & $176(15.7 \%)$ & \\
aphakic & $3(0.2 \%)$ & $3(0.3 \%)$ & \\
Others & $5(0.4 \%)$ & $5(0.4 \%)$ & \\
\hline
\end{tabular}

Information about gender, age, family income, education, medical insurance type, commute, satisfaction, awareness and district of patients who had received or not received cataract surgery

Two thousand two hundred thirty-four patients supplied complete information required in the questionnaire. It showed that more female subjects $(64.6 \%)$ than male subjects (35.4\%) accepted cataract surgery among the 404 patients who had surgery history. Of the 404 patients, $36.4 \%$ of surgery patients were equal or older than 80 . However, the most common age range in no surgery population were 60 to 70 years old (34.9\%) and 70 to 80 years old $(33.6 \%)$. The constituent ratio of age in surgery group and no surgery group were significantly different $(p<0.0001)$. There were no significant differences between patients who had received surgery and those who had not with regard to family income level. For patients who received surgery, 92.1\% had urban medical insurance; for patients who did not receive surgery, 87. $0 \%$ had urban medical insurance $(p=0.036)$. Commute times were longer among those who had received surgery $(p=0.0115)$. Patients in the surgery group were more satisfied with local medical service than people in the "no surgery" group $(p=0.0048)$. Most of the patients in the surgery group were from urban area (55.2\%), whereas patients from rural area composed a larger portion $(54.5 \%)$ of the "no surgery" group $(p=0.0004)$. Details are shown in Table 3.

In order to investigate different personal reasons for unacceptance of cataract surgery, we designed a question in the questionnaire: Why haven't you accepted cataract surgery previously before the survey? There were 287 patients supplied their answers. Several kinds of answers were collected. The most frequent answers were that "I don't think that cataract has much influence on my life. My present visual acuity still makes do" and "I did not know that my visual acuity was impaired by cataract". Details were shown in Table 4.

\section{Correlations between gender, age, family income, education, medical insurance type, commute, satisfaction, awareness, district and surgery status among cataract patients with vision impairment}

To investigate the correlations between possible factors influencing cataract surgery among interviewees, we performed multivariable linear regression analysis. The results indicated that gender, age, awareness, district type, family income and commute time were significantly correlated with cataract surgery. Patients with the following features were more likely to receive cataract surgery: female $(\mathrm{OR}(95 \% \mathrm{CI})$ for male $=0.649(0.506,0$. $833), p=0.0007)$, over 80 years old $(\mathrm{OR}(95 \% \mathrm{CI})=2$. $521(1.535,4.140), \quad p=0.0003)$, better awareness $(\mathrm{OR}(95 \% \mathrm{CI})=1.034 \quad(1.028,1.040), \quad p<0.0001)$, lower family income $(\mathrm{OR}(95 \% \mathrm{CI})$ for income $\geq 5000=0.579(0$. $400,0.837), p=0.0036)$ and longer commute time $(\mathrm{OR}(95 \% \mathrm{CI})$ for one transfer $=1.344(1.033,1.749), p=0$. 0278). The latter two features represent a significant departure from several previous reports. To clarify the reasons that patients with lower income and inconvenient commutes were more prone to receive cataract surgery than people with higher income and more convenient transportation conditions, we further analysed patients from rural and urban areas separately. We found that these phenomena existed in urban but not rural residents. Details are shown in Table 5.

\section{Discussion}

Surgery remains the major option for cataract treatment. However, many patients in developing countries only seek cataract surgery in later stages of cataract progression. Severe complications, such as phacolytic and phacomorphic glaucoma, could occur at these later stages. In this study, patients who had visual impairment caused by cataracts completed a questionnaire survey. The survey was executed in the form of a face-to-face interview. Compared to some other studies [23-25] that were conducted by telephone, this form of survey was more appropriate for collecting broader information.

To ensure the necessity of cataract surgery in those patients, we performed ophthalmologic examination of all interviewees. Subjects suffering from other visual impairments, such as high myopia, corneal opacity, agerelated macular degeneration, diabetic retinopathy and glaucoma, were excluded, as these comorbidities could confound our results. With regard to lens status, there were more "IOLs" implanted in Xuhui than in Baoshan (15.7\% vs $10.5 \%$, respectively, $p=0.004)$. This result was in accordance with the fact that the surgery rate was lower in Baoshan district. 
Table 3 Gender, age, family income, education, medical insurance type, commute, satisfaction, awareness, district of patients accepted and unaccepted cataract surgery

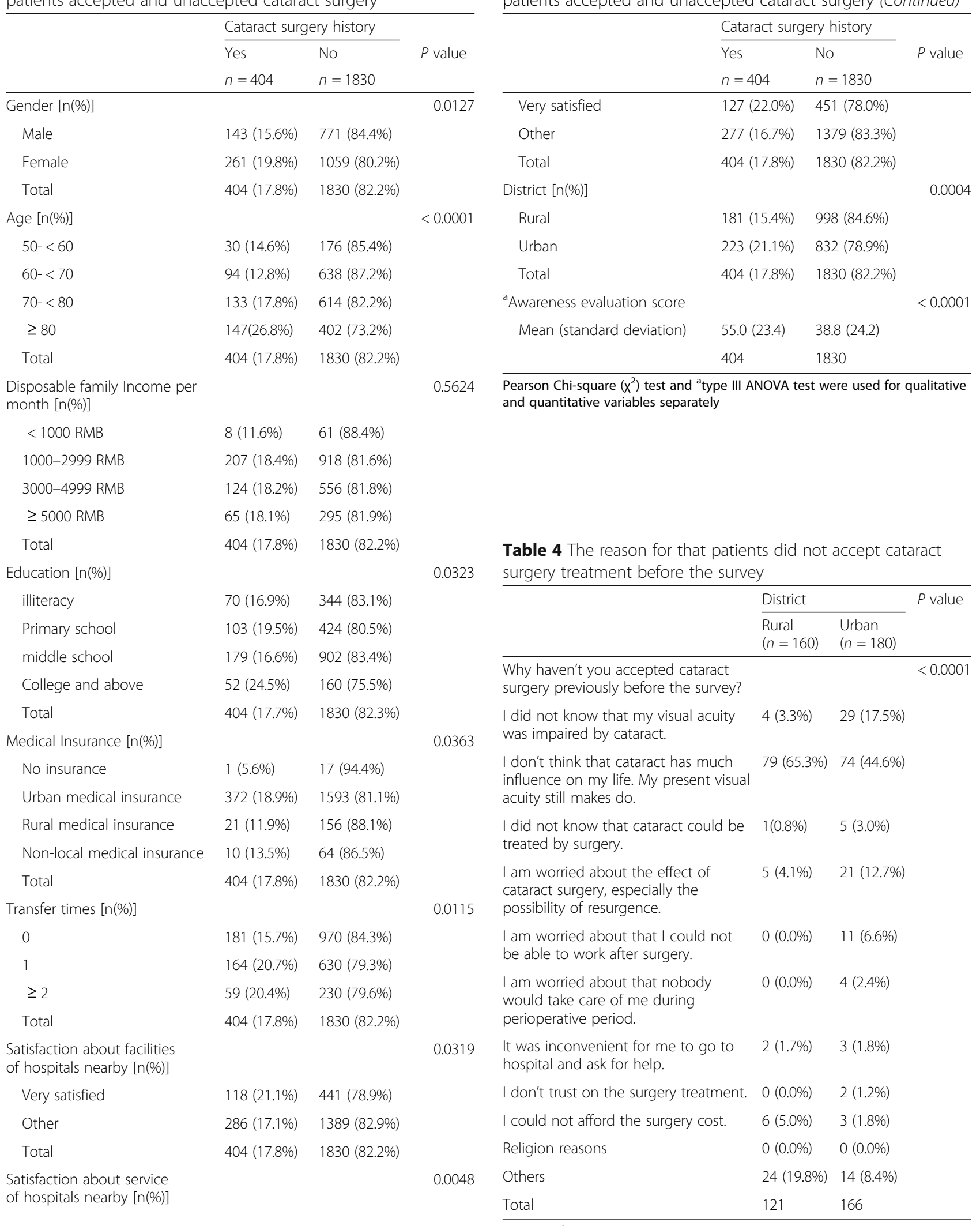

Pearson Chi-square $\left(x^{2}\right)$ test

Table 3 Gender, age, family income, education, medical insurance type, commute, satisfaction, awareness, district of patients accepted and unaccepted cataract surgery (Continued)

Table 4 The reason for that patients did not accept cataract surgery treatment before the survey

Why haven't you accepted cataract

\section{,}


Table 5 Logistic regression of the correlation between gender, age, family income, education, medical insurance type, commute, satisfaction, awareness, district and surgery status

\begin{tabular}{|c|c|c|c|c|c|c|c|c|c|c|c|c|c|}
\hline \multirow[t]{2}{*}{ Factors } & & \multicolumn{4}{|c|}{ Rural \& urban } & \multicolumn{4}{|l|}{ Rural } & \multicolumn{4}{|l|}{ Urban } \\
\hline & & $\overline{O R}$ & $95 \% \mathrm{Cl}$ & & $P$ value & $\overline{O R}$ & $95 \% \mathrm{C}$ & & $P$ value & $\overline{\mathrm{OR}}$ & $95 \% \mathrm{C}$ & & $P$ value \\
\hline \multirow[t]{2}{*}{ Gender } & Female & \multicolumn{4}{|c|}{ reference } & \multicolumn{4}{|c|}{ reference } & \multicolumn{4}{|c|}{ reference } \\
\hline & Male & 0.649 & 0.506 & 0.833 & 0.0007 & 0.635 & 0.439 & 0.918 & 0.0158 & 0.660 & 0.467 & 0.931 & 0.0178 \\
\hline \multirow[t]{4}{*}{ Age } & $50-<60$ & \multicolumn{4}{|c|}{ reference } & \multicolumn{4}{|c|}{ reference } & \multicolumn{4}{|c|}{ reference } \\
\hline & $60-69$ & 0.801 & 0.494 & 1.298 & 0.3675 & 0.627 & 0.340 & 1.155 & 0.1343 & 1.259 & 0.548 & 2.893 & 0.5876 \\
\hline & $70-79$ & 1.182 & 0.733 & 1.908 & 0.4931 & 0.875 & 0.469 & 1.632 & 0.6739 & 1.872 & 0.829 & 4.229 & 0.1313 \\
\hline & $>79$ & 2.521 & 1.535 & 4.140 & 0.0003 & 1.841 & 0.947 & 3.582 & 0.0721 & 4.132 & 1.808 & 9.444 & 0.0008 \\
\hline \multirow[t]{3}{*}{ Income } & $\leq 2999$ & \multicolumn{4}{|c|}{ reference } & \multicolumn{4}{|c|}{ reference } & \multicolumn{4}{|c|}{ reference } \\
\hline & 3000-4999 & 0.720 & 0.545 & 0.950 & 0.0203 & 0.731 & 0.477 & 1.120 & 0.1501 & 0.709 & 0.486 & 1.032 & 0.0728 \\
\hline & $\geq 5000$ & 0.579 & 0.400 & 0.837 & 0.0036 & 0.904 & 0.484 & 1.688 & 0.7506 & 0.501 & 0.313 & 0.804 & 0.0042 \\
\hline \multirow[t]{4}{*}{ Education } & illiteracy & \multicolumn{4}{|c|}{ reference } & \multicolumn{4}{|c|}{ reference } & \multicolumn{4}{|c|}{ reference } \\
\hline & primary school & 1.282 & 0.880 & 1.867 & 0.1963 & 1.154 & 0.693 & 1.921 & 0.5814 & 1.485 & 0.831 & 2.652 & 0.1816 \\
\hline & middle school & 1.104 & 0.751 & 1.622 & 0.6159 & 0.923 & 0.536 & 1.589 & 0.7735 & 1.325 & 0.744 & 2.360 & 0.3391 \\
\hline & college and above & 1.375 & 0.831 & 2.275 & 0.2151 & 0.867 & 0.402 & 1.869 & 0.7151 & 2.141 & 1.043 & 4.392 & 0.0379 \\
\hline \multirow[t]{3}{*}{ Social insurance } & $\begin{array}{l}\text { without insurance \& } \\
\text { non-local insurance }\end{array}$ & 0.762 & 0.382 & 1.522 & 0.4419 & 0.747 & 0.330 & 1.693 & 0.4855 & 0.718 & 0.188 & 2.744 & 0.6284 \\
\hline & urban health insurance & \multicolumn{4}{|c|}{ reference } & \multicolumn{4}{|c|}{ reference } & \multicolumn{4}{|c|}{ reference } \\
\hline & rural health insurance & 0.904 & 0.526 & 1.555 & 0.7158 & 0.812 & 0.446 & 1.479 & 0.4956 & 2.875 & 0.500 & 16.515 & 0.2366 \\
\hline \multirow[t]{3}{*}{ Hospital accessibility } & through bus & \multicolumn{4}{|c|}{ reference } & \multicolumn{4}{|c|}{ reference } & \multicolumn{4}{|c|}{ reference } \\
\hline & one transfer & 1.344 & 1.033 & 1.749 & 0.0278 & 1.143 & 0.762 & 1.716 & 0.5185 & 1.466 & 1.030 & 2.0872 & 0.0336 \\
\hline & $\geq$ twice transfer & 1.419 & 0.988 & 2.039 & 0.0581 & 1.120 & 0.650 & 1.931 & 0.6826 & 1.760 & 1.068 & 2.901 & 0.0266 \\
\hline Satisfaction about hospital & others & referes & nce & & & refere & רce & & & referen & & & \\
\hline & satisfied & 0.667 & 0.369 & 1.203 & 0.1780 & 0.654 & 0.284 & 1.506 & 0.3184 & 0.676 & 0.285 & 1.605 & 0.3747 \\
\hline Satisfaction about medical & others & referer & nce & & & refere & & & & referen & & & \\
\hline se & satisfied & 1.632 & 0.918 & 2.903 & 0.0952 & 1.363 & 0.617 & 3.012 & 0.4435 & 1.786 & 0.756 & 4.219 & 0.1858 \\
\hline Awareness score & - & 1.034 & 1.028 & 1.040 & $<0.0001$ & 1.039 & 1.030 & 1.047 & $<0.0001$ & 1.031 & 1.023 & 1.039 & $<0.0001$ \\
\hline District & Baoshan & referer & nce & & & - & & & & - & & & \\
\hline & Xuhui & 1.524 & 1.181 & 1.967 & 0.0012 & & & & & & & & \\
\hline
\end{tabular}

The Logistic analysis (full model)

There are many factors influencing cataract surgery in rural and urban populations. After referring to the reported studies and the local features of Shanghai city, we chose these factors described in the study to do the questionnaire survey. According to our results, $17.8 \%$ of subjects (417 out of 2342) had received cataract surgery. The surgery rate in patients with the following features was higher: female, over 80 years old, low family income, longer commute time, better health awareness, and urban residents. Patients with disposable family income greater than 3000 Chinese Yuan (about 470 US Dollars) per month were less willing to commit to surgery. Some of our results were similar to previous reports. However, a unique observation was that patients in urban areas with lower family income and longer commutes were even more prone to receive surgery. This is distinct from other studies which reported that economic and commute difficulties could pose a barrier to cataract surgery among patients with visual impairment. A possible reason for this may be that partial reimbursement of surgery costs by the Social Security Administration is profitable for hospitals providing medical service. Thus, this may be an important income source for many public hospitals. Before 2015, the reimbursement ratio of urban health insurance was much higher than that of rural health insurance $(70 \%$ versus $50 \%)$ in Shanghai, which means that hospitals could benefit more from patients having urban health insurance. In recent years, cataract surgery promotion policies for patients from poor economic backgrounds have been widely promoted by the Shanghai government. Hospitals were encouraged to screen proper cataract patients with poor economy background to perform cataract surgeries, and there were shuttle buses from hospitals to pick up patients in 
inconvenient areas to surgery performing hospitals and send them back to home after surgeries. In such situations, more patients with low income and inconvenient commutes accepted cataract surgeries on the contrary. Due to the reimbursement profit gap between urban health insurance and rural health insurance, hospitals were much more willing to perform such screenings among populations in urban areas. The reasons listed above could cause more patients in urban area to receive cataract surgery even though their family income is low and their commute is inconvenient. This study indicates the important influence of government policy on cataract surgery promotion even though economic and commute difficulties still exist. Better policy support is needed for patients with rural health insurance. Visual impairment in different distance and cataract surgery practice was another important research topic. It was possible that patients with distant visual impairment may not have surgery because that they could still handle with daily life with near vision. It is worthy to do further study to investigate this topic.

According to the survey, the most frequent answers to why the patients did not accept cataract surgery were that "I don't think that cataract has much influence on my life. My present visual acuity still makes do" and "I did not know that my visual acuity was impaired by cataract". It could be explained by the reasons as follows:most of the patients were old people and work did not play an important role in their life, most of the patients did not ask for much for their quality of life, and their awareness about cataract needed improving. Health education could be effective for improving the awareness and cataract surgery practice in those patients.

During the investigation, we did general ophthalmologic evaluation for the patients. However, in the present study, we mainly used the clinical data to screen out those subjects with visual impairment caused by cataract and did questionnaire survey to the patients, so the basic clinical data related to cataract were shown, including visual acuity, intraocular pressure and lens status. In further study derived from the investigation, we will focus on the clinical examination and more clinical data would be analysed.

Patients' health awareness is an important factor influencing surgery in general. Our results show that the surgery rate was higher among patients with better health awareness level, which in turn demonstrates the importance of health awareness in promoting cataract surgery. Since 1998, a large number of public health system building projects have been executed and promoted by the Shanghai Municipal government, the Center for Disease Control and the Shanghai Eye Disease Prevention \& Treatment Center. Patient education has been widely promoted at each community health care centre. This work has improved health awareness in both rural and urban areas and has promoted cataract surgery in general.

The patients included in the study have different awareness status about the cataract disease. The awareness status was influenced by various reasons, such as patients' education level, the health literacy, the health service access, and the health service quality [26]. All those factors could have influence on the patients' awareness and the surgery practice, and it is very important to clarify the influence of the health service access on the awareness. We will do further study to discuss the influence of various factors on awareness on surgery practice.

\section{Conclusions}

Shanghai is the city with the largest population in China, and it is one of the biggest cities worldwide. As a municipality, its administrative level is equal to that of a province in China. The scale and importance of this city indicates the degree to which our study may be representative of many metropolitan cities and their adjacent rural areas in China. In order to prove the effectiveness of government policies, further cohort studies with more controls will be needed, which could supply stronger evidence to support our viewpoint. This study provides information for policymakers to consider how to increase cataract surgery rates and reduce vision impairment caused by cataracts across the entire country of China.

\section{Abbreviations \\ CSR: Cataract surgery rate; PVA: Presented visual acuity}

\section{Acknowledgements}

We thank all patients and their families for kindly participating in the study.

\section{Funding}

This study was financially supported by the Shanghai Municipal Commission of Health and Family Planning Grant (No. 201440529).

Availability of data and materials

The datasets generated during and/or analysed during the current study are available from the corresponding author upon reasonable request.

\section{Authors' contributions \\ YX Design and execution of the study, data collection and manuscript preparation; JH Design and execution of the study, data collection and analysis; SL Execution of the study, data collection and analysis; BZ Execution of the study; JZ Design of the study; SR manuscript preparation and review; $\mathrm{LL}$ Design and execution of the study, manuscript preparation; HZ Design of the study, manuscript preparation. All authors read and approved the final manuscript.}

\section{Ethics approval and consent to participate}

This study was approved by the Ethics Committee of the Shanghai Eye Disease Prevention \& Treatment Center. A written informed consent was obtained from each patient for the investigation.

Consent for publication

Inform consent were acquired from each enrolled patient.

Competing interests

The authors declare that they have no competing interests. 


\section{Publisher's Note}

Springer Nature remains neutral with regard to jurisdictional claims in published maps and institutional affiliations.

\section{Author details}

'Shanghai Eye Disease Prevention \& Treatment Center / Shanghai Eye Hospital; Shanghai Key Laboratory of Ocular Fundus Diseases; Shanghai General Hospital; Shanghai Engineering Center for Visual Science and Photomedicine, 380 Kangding Road, Shanghai 200040, China. ${ }^{2}$ Brien Holden Vision Institute and SOVS, University of New South Wales, Sydney, NSW, Australia.

Received: 30 October 2017 Accepted: 3 April 2018 Published online: 18 April 2018

\section{References}

1. Khairallah M, Kahloun $\mathrm{R}$, Bourne $\mathrm{R}$, Limburg H, Flaxman SR, Jonas JB, et al. Number of people blind or visually impaired by cataract worldwide and in world regions, 1990 to 2010. Invest Ophthalmol Vis Sci. 2015;56:6762-9.

2. Gonzalez-Salinas R, Guarnieri A, Guirao Navarro MC, Saenz-de-Viteri M. Patient considerations in cataract surgery - the role of combined therapy using phenylephrine and ketorolac. Patient Prefer Adherence. 2016;10:1795-801.

3. Blindness in the elderly [editorial]. Lancet. 2008;372(9646):1273.

4. Brian G, Taylor H. Cataract blindness - challenges for the $21^{\text {st }}$ century. Bull World Health Organ. 2001;79:249-56.

5. PwC (PricewaterhouseCoopers). The price of sight: the global cost of eliminating avoidable blindness. Final report for the Fred hollows foundation. Melbourne: PricewaterhouseCoopers; 2012

6. Liang Yb1, Friedman DS, Wong TY, Zhan SY, Sun LP, Wang JJ, et al. Prevalence and causes of low vision and blindness in a rural Chinese adult population: the Handan eye study. Ophthalmol. 2008;115:1965-72.

7. Tang Y, Wang X, Wang J, Huang W, Gao Y, Luo Y, et al. Prevalence of agerelated cataract and cataract surgery in a Chinese adult population: the Taizhou eye study. Invest Ophthalmol Vis Sci. 2016;57:1193-200.

8. China Disabled Person's Federation (CDPF). Statistics yearbook on the undertakings of people with disabilities in China. Beijing: CDPF Information Center; 2005. p. 3-99.

9. Zhao JL. To promote "vision 2020" initiative under the new situation in China. Zhonghua Yan Ke Za Zhi. 2011;47:769-72.

10. Chen $T$, Jin $L$, Zhou Z, Huang $Y$, Yan $X$, Liu T, et al. Factors influencing the output of rural cataract surgical facilities in China: the SHARP study. Invest Ophthalmol Vis Sci. 2015;56:1283-91.

11. Zhao J, Ellwein LB, Cui H, Ge J, Guan H, Lv J, et al. Prevalence and outcomes of cataract surgery in rural China the China nine-province survey. Ophthalmol. 2010;117:2120-8.

12. Information about national cataract surgery operations in 2014. National health and family planning commission of the people's republic of China. 2015. http://www.moh.gov.cn/yzygj/s7653/201503/ 9aa3cc022c744b28845c121209166491.shtml. Accessed 31 Mar.

13. Showcase - VISION 2020 Latin America. Graph. Regional CSR, 2005-2013. 2013. https://www.iapb.org/iapb-membership/council-of-membersmeetings/council-meetings-archive/paris-2014/showcase-vision-2020-latinamerica/.

14. Chu CJ, Johnston RL, Buscombe C, Sallam AB, Mohamed Q, Yang YC, et al. Risk factors and incidence of macular edema after cataract surgery: a database study of 81984 eyes. Ophthalmol. 2016;123:316-23.

15. Yin Q, Hu A, Liang Y, Zhang J, He M, Lam DS, et al. A two-site, populationbased study of barriers to cataract surgery in rural China. Invest Ophthalmol Vis Sci. 2009:50:1069-75.

16. Xu L, Cui T, Zhang S, Sun B, Zheng Y, Hu A, et al. Prevalence and risk factors of lens opacities in urban and rural Chinese in Beijing. Ophthalmol. 2006:113:747-55.

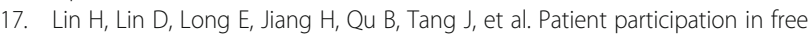
cataract surgery: a cross-sectional study of the low-income elderly in urban China. BMJ Open. 2016;6:e011061.

18. Wang Y, Wang J, Maitland E, Zhao Y, Nicholas S, Lu M. Growing old before growing rich: inequality in health service utilization among the mid-aged and elderly in Gansu and Zhejiang provinces, China. BMC Health Serv Res. 2012;12:302
19. Jin Y, Zhang Q, Shan L, Li SP. Characteristics of venture capital network and its correlation with regional economy: evidence from China. PLoS One. 2015;10:e0137172

20. Sun J, Guo Y, Wang X, Zeng Q. mHealth for aging China: opportunities and challenges. Aging Dis. 2016;7:53-67.

21. He J, Lu L, He X, Xu X, Du X, Zhang B, et al. The relationship between crystalline lens power and refractive error in older Chinese alduts: the shanghai eye study. PLoS One. 2017;12:e0170030.

22. Zhao J, Xu X, Ellwein LB, Cai N, Guan $H$, He M, et al. Prevalence of Vision Impairment in Older Adults in Rural China in 2014 and Comparisons With the 2006 China Nine-Province Survey. Am J Ophthalmol. 2018;185:81-93.

23. Plonczak AM, McArthur GJ, Goldsmith N, Horwitz M. Hand Therapist Led Follow-up for Paediatric Hand Trauma - a Retrospective Study of 139 Closed Hand Injuries. Ortop Traumatol Rehabil. 2017;19:531-6.

24. Zhu Z, Wang L, Young CA, Huang S, Chang BH, He M. Cataract-related visual impairment corrected by cataract surgery and 10-year mortality: the Liwan eye study. Invest Ophthalmol Vis Sci. 2016:57:2290-5.

25. Zhang XJ, Jhanji V, Leung CK, Li EY, Liu Y, Zheng C, et al. Barriers for poor cataract surgery uptake among patients with operable cataract in a program of outreach screening and low-cost surgery in rural China. Ophthalmic Epidemiol. 2014;21:153-60.

26. Shrestha MK, Guo CW, Maharjan N, Gurung R, Ruit S. Health literacy of common ocular diseases in Nepal. BMC Ophthalmol. 2014;14:2.

\section{Ready to submit your research? Choose BMC and benefit from:}

- fast, convenient online submission

- thorough peer review by experienced researchers in your field

- rapid publication on acceptance

- support for research data, including large and complex data types

- gold Open Access which fosters wider collaboration and increased citations

- maximum visibility for your research: over $100 \mathrm{M}$ website views per year

At BMC, research is always in progress.

Learn more biomedcentral.com/submissions 